\title{
The dynamics of gynodioecy in Plantago lanceolata L. I. Frequencies of male-steriles and their cytoplasmic male sterility types
}

\author{
ANITA A. DE HAAN*, RENE M. J. M. LUYTEN, TANJA J. M. T. BAKX-SCHOTMAN \& \\ JOS M. M. VAN DAMME \\ Netherlands Institute of Ecology, NIOO-CTO, PO Box 40, 6666 ZG Heteren, the Netherlands
}

\begin{abstract}
The maintenance of a gynodioecious breeding system (hermaphrodites and male-steriles) was studied in Plantago lanceolata. Cytoplasmic-nuclear inheritance is important in the maintenance of male-steriles. The male-sterile trait is cytoplasmically based (CMS), and male fertility can be restored by nuclear genes. Male-sterile frequencies differ among populations. Several hypotheses can be considered. (1) In each population a different equilibrium could be optimal because of environmentally dependent fitnesses. (2) None of the populations has reached an equilibrium (yet). (3) The populations are in different phases of a dynamic equilibrium, i.e. limit cycles. The last two explanations both predict a dynamic process, a continuous change within populations. Sex phenotype frequencies and their underlying gene frequencies were assessed. Sex phenotype frequencies changed over years within populations. We showed that these changes resulted from changes in genotype composition, which favours the two hypotheses ( 2 and 3 ) that predict a dynamic process. CMS-type frequencies were estimated using mtDNA markers. Among populations, CMS types differed in frequencies. CMSI and CMSIII seemed to exclude each other, and CMSII types occurred in all populations. In all populations, CMSI appeared to be less restored than the other CMS types. This was not expected on the basis of either of the two theoretical models that included dynamics (hypotheses 2 and 3 ).
\end{abstract}

Keywords: cytoplasmic male sterility, dynamic equilibrium, gynodioecy, male sterility, Plantago.

\section{Introduction}

In species with a gynodioecious breeding system, females co-occur with hermaphrodites. Females are effectively male-sterile, whereas hermaphrodites have both a female and male function. In several species, the inheritance of this breeding system is based on cytoplasmic and nuclear factors (for reviews, see Hanson \& Conde, 1985; Braun et al., 1992). The male-sterile trait is cytoplasmically inherited (CMS) and male fertility can be restored by nuclear genes (restorer alleles).

In Plantago lanceolata L. (ribwort plantain), two cytoplasmic male-sterile phenotypes can be distinguished: MS1 and MS2. A third, rare, male-sterile

\footnotetext{
${ }^{*}$ Correspondence and present address: Department of Genetics, University of Oulu, PO Box 333, 90571 Oulu, Finland. E-mail: dehaan@sun3.oulu.fi
}

type MS3 shows nuclear inheritance (Van Damme \& Van Delden, 1982). Van Damme \& Van Delden (1982) showed that MS1 and MS2 represent different CMS types and can be restored by different restorer loci. De Haan et al. (1997a) showed that within P. lanceolata a total of four CMS types can be distinguished. The MS1 phenotype has the CMSI type, whereas the MS2 phenotype is expressed in plants with either CMSIIa or CMSIIb. CMSIII does not segregate cytoplasmic male-steriles (De Haan et al., 1997a). This could be the result of complete restoration at all loci for the genotypes used by De Haan et al. (1997a); alternatively, CMSIII could be a so-called normal cytoplasm.

The restoration of male fertility has been shown to be complex (Van Damme, 1983). Two to four loci were found with either dominant or recessive restorer alleles. Two loci for CMSI showed epistatic 
effects (De Haan et al., 1997b). In each case, malesterile (MS) plants carry no dominant restorer alleles or are heterozygous at the recessive loci. Intermediate types (IN) show a mix of MS and hermaphrodite $(\mathrm{H})$ anthers and/or intermediate-type anthers (Van Damme \& Van Delden, 1982). The inheritance is not unravelled, but IN carries more restorer alleles than MS, and fewer than $\mathrm{H}$. Hermaphrodites carry at least one dominant restorer allele or are homozygous restored at recessive loci.

The maintenance of gynodioecy has been the object of several theoretical studies (Charlesworth \& Charlesworth, 1978; Ross, 1980; Frank, 1989; Gouyon et al., 1991). Cytoplasmic-nuclear inheritance has been found to be important for the maintenance of the system. Because of cytoplasmicnuclear inheritance, selection takes place at different levels. First, the cytoplasmic male-sterile can spread in the population if it has a higher seed production than the hermaphrodite ('MS fitness advantage') (reviewed by Couvet et al., 1990). Secondly, gynodioecy can be maintained only if the nuclear restorer alleles do not reach fixation. Thus, negative effects on the fitness of restorer alleles must be assumed ('cost of restoration').

Different frequencies of male-steriles have been found among populations of gynodioecious species, for example in Beta maritima (Cuguen et al., 1994), $P$. coronopus (Koelewijn \& Van Damme, 1995), $P$. lanceolata (Van Damme \& Van Delden, 1982) and Thymus vulgaris (Belhassen et al., 1989). There are three hypotheses that can explain differences in sex phenotype composition among populations.

1 The fitness differences of sex phenotypes are dependent on environmental conditions, which vary among populations. Thus, the relative sex phenotype frequencies could be different in different populations. Krohne et al. (1979) showed a positive correlation between male-sterile frequencies in $P$. lanceolata and moisture, indicating that there might be a relationship between conditions and sex phenotype composition.

Two theoretical models assumed different ways in which the fixation of the restorer alleles is prevented.

2 All populations are in disequilibrium. As a result of stochastic processes, gene frequencies, and subsequent sex phenotype frequencies, vary in time and place. Couvet et al. (1986, 1990) showed that in Thymus vulgaris a negative relationship exists between the age of the population and male-sterile frequency. Frank (1989) showed that the restorer alleles can be prevented from fixation by assuming stochasticity and sufficient genetic variation in CMS types. Male-steriles were maintained even if the 'MS fitness advantage' and 'cost of restoration' were relatively low.

3 Gouyon et al. (1991) explained the differences between populations with a dynamic equilibrium. Depending on the parameters, limit cycles occurred, instead of point equilibria. Differences in malesterile frequencies between populations were explained as populations being in different phases of the limit cycle. The 'MS fitness advantage' and 'cost of restoration' need to be relatively high in order to maintain gynodioecy. Hypotheses (2) and (3) both predict a continuous change within populations, whereas hypothesis (1) predicts stable gene and sex phenotype composition in populations in which no environmental change is occurring.

In this study, we test these hypotheses using the differences in male-sterile frequencies among populations of $P$. lanceolata. The first question we address is whether the maintenance of gynodioecy is a dynamic process: are sex-type frequencies in populations changing over time? The second question is: what are the underlying gene frequencies of MS in populations? And how do populations differ from each other in CMS type and restorer frequencies?

\section{Materials and methods}

\section{Field scores}

Plantago lanceolata $\mathrm{L}$. is a self-incompatible perennial species with half-life time estimates from 1 to 7 years (Mook et al., 1992). To assess sex phenotype frequencies over several years and their underlying CMS-type frequencies, eight populations in the Netherlands were chosen on the basis of differences in sex phenotype frequencies. Reitma (Rei), Heteren (Ht), Naterseweg (Nat), Veneweg (Ven), Koudum (Kou) and Leek consist of more than 1000 individuals, Junner Koeland (Jun) and Brummen $(\mathrm{Bm})$ consist of about 400 individuals. Five sex phenotypes were distinguished: MS1, MS2, IN1, IN2 and $\mathrm{H}$. MS plants do not produce any pollen, IN show a mix of non-pollen- and pollen-containing anthers and $\mathrm{H}$ produces only pollen-containing anthers. MS1 and IN1 vs. MS2 and IN2 can be distinguished on the basis of flower morphology (Van Damme \& Van Delden, 1982).

In 1991, 1992, 1993 and 1994, the frequencies of sex phenotypes were assessed at the peak of flowering in four populations of $P$. lanceolata in the Netherlands, namely Leek, Rei (not in 1994), Ven and 
Nat. The plants were scored along a transect of blocks of $1 \mathrm{~m}$ by $1 \mathrm{~m}$. In order to score about 200 plants, the length of the transects differed depending on the density: Leek $90 \mathrm{~m}$, Rei $30 \mathrm{~m}$, Ven $60 \mathrm{~m}$ and Nat $30 \mathrm{~m}$. In addition, four other populations were screened in 1991: Bm in a transect of $1 \mathrm{~m}$ by $30 \mathrm{~m}$ and Kou as part of a verge of $5 \mathrm{~m}$ by $100 \mathrm{~m}$; Ht and Jun plants were scored randomly over the population. These eight populations were also used for the estimation of the CMS-type frequencies (see below).

\section{Temporal variation}

Two experiments were performed to study sex phenotype frequency changes over time. First, Van Damme \& Van Delden (1982) scored sex-type frequencies in a large number of populations in the Netherlands in a random fashion; 12 of those populations were rescored between 1992 and 1994 in the same way. Secondly, we compared the sex phenotype frequencies in the field with the frequencies in the seed generation. To estimate the frequencies of the sex phenotypes in the seed generation, one ripe spike per plot of the transect was collected in 1991 (except Nat in 1992) representing a half-sib family. In $\mathrm{Ht}$ and Jun, a random seed sample was taken. Ten seeds of each family were grown in the experimental garden, and the sex phenotypes of the plants were scored. Of the $\mathrm{Ht}$ and Jun populations 525 and 396 flowering plants were screened respectively.

Seeds were germinated in a Petri dish, and seedlings were precultured in the greenhouse for about 4 weeks in Jiffy pots and then transferred to the experimental garden. Germination was at least 80 per cent and death of seedlings was negligible. The sandy soil of the experimental garden was moderately fertilized and sprinkled with water when necessary. The proportion of flowering plants was more than 90 per cent.

Changes in sex-type frequencies within populations were analysed using Pearson rank correlation. Differences in sex-type frequencies over years within a population (1991 minus 1993) were compared with the differences between the frequencies of sex phenotypes in the field and in the seed generation (1991 minus seed generation). The transects of four populations (Rei, Nat, Leek and Ven) were divided into blocks of $10 \mathrm{~m}$ by $1 \mathrm{~m}$, which were treated as independent samples in the analysis.

\section{The estimation of the gene frequencies}

CMS (geno)type frequencies were based on the frequencies of mtDNA variants. MtDNA patterns were revealed with restriction enzyme HindIII and a $P$. lanceolata $\mathrm{mt}$ probe $\mathrm{pPl} 311$ (Rouwendal et al., 1987). DNA was isolated by the method of Rogers \& Bendich (1988) with some modifications (De Haan et al., 1997a). For labelling of the probe a nonradioactive method (digoxigenin; according to Boehringer-Mannheim) was used. Restriction fragment length polymorphism (RFLP) analyses are further described in De Haan et al. (1997a). The plant material for the assessment of CMS-type frequencies originated from two collections. First, one plant per family of the seed generation was taken. Secondly, flowering plants were collected in Rei and Ven. Only $\mathrm{H}$ plants were collected; the mtDNA patterns of MS plants in the two populations were known from the seed generation sample: MS1 in Ven always showed the mtDNA pattern A, and MS2 in Rei always showed mtDNA pattern D. In order to obtain an accurate estimate of $\mathrm{mt} \mathrm{A}$ in Ven, and $\mathrm{mt} \mathrm{D}$ in Rei in 1993, the frequency $(p)$ was corrected $\left(p \mathrm{Mt}_{i}=p \mathrm{Mt}_{i}\right.$ in $\mathrm{H}$ sample $1993+p \mathrm{MS}$ in field 1993).

The estimated restorer frequencies were calculated as follows: $p \mathrm{R}_{i} \exp =p \mathrm{CMS}_{i}-p \mathrm{MS}_{i} \cdot p \mathrm{R}_{i}$ represents the frequency of plants with the $\mathrm{CMS}_{i}$ genotype that are hermaphrodite and gives an overall estimate of the restorer frequency. $p \mathrm{CMS}_{i}$ was based on material from the seed generation in all populations, but in Rei and Ven also on plants sampled in 1993. We chose to pool the results to estimate $\mathrm{CMS}_{i}$. As an estimate, $p \mathrm{MS}_{i}$ was averaged over the years 1991-94. The observed restorer frequencies for Ven, Bm, Nat and Leek were calculated on the basis of the sex scores of the half-sib families of which the mtDNA pattern was known from the molecular analysis of one of the sibs: $p \mathrm{R}_{i}$ observed $=p \mathrm{H}_{i}+p \mathrm{IN}_{i}$. For each mtDNA pattern the restorer frequencies of the families with that mtDNA pattern were averaged over the population. The restorer frequencies for Rei, Kou, Ht and Jun were based on the phenotypes of the sampled plants instead of on progeny analysis. For statistical analysis, the frequencies were $\arcsin \sqrt{ } x$ transformed.

\section{Results}

\section{Dynamics of gynodioecy}

In 12 populations, sex phenotype frequencies were scored randomly over the whole population, defined as a physical unit such as a verge or a meadow. Van Damme \& Van Delden (1982) scored the populations between 1978 and 1982; we rescored parts of 
the same populations 12 years later. The results are shown in Table 1. The differences between the two years for each population were tested with a $\chi^{2}$-test. Of the 12 populations, eight showed a significant change over 12 years.

Table 2 shows that, within 2 or 3 years, sex phenotype frequencies were significantly different. To check whether those differences resulted from changes in genotype composition, the differences between the years were compared with the sex phenotype frequency in the seed generation of 1991 (Fig. 1). A significant correlation was found between the change in sex phenotype frequencies in the field in 2 years (1991 minus 1993) and the difference between the field score in 1991 and its seed generation ( $r=0.88, P<0.001$, between rank scores). This means that the observed changes in sex phenotype frequencies in the populations over years could result from changes in genotype composition.

\section{Gene frequencies: CMS type and restorer alleles}

Plants from eight populations were screened for mtDNA variation. More than 20 mitochondrial variants were found with the enzyme-probe combination HindIII-pPl311 in a total of 518 plants screened. In Fig. 2(a,b), mtDNA patterns of 21 plants are shown. When interpreting the mtDNA patterns faint fragments were ignored.

The populations Rei and Ven were sampled twice, but no significant difference in mtDNA variation was found between years (Rei: $\chi_{2}^{2}=3.22$; Ven $\left.\chi_{5}^{2}=4.37\right)$ and the samples were taken together. Each of the eight populations had its own distribu-

Table 1 Sex-type frequencies (MS1, IN1, MS2, IN2 and H) in percentages for 12 populations of Plantago lanceolata (for abbreviations see Van Damme \& Van Delden, 1982) scored in 2 years

\begin{tabular}{|c|c|c|c|c|c|c|c|c|c|c|}
\hline Population & Year & MS1 & IN1 & MS2 & IN2 & $\mathrm{H}$ & TOT & $\chi^{2}$ & d.f. & $P$ \\
\hline $\mathrm{Aa}$ & $\begin{array}{l}1978 \\
1992\end{array}$ & $\begin{array}{l}0.0 \\
0.0\end{array}$ & $\begin{array}{l}0.0 \\
0.4\end{array}$ & $\begin{array}{l}0.3 \\
0.4\end{array}$ & $\begin{array}{l}0.3 \\
0.0\end{array}$ & $\begin{array}{l}99.5 \\
99.2\end{array}$ & $\begin{array}{l}765 \\
242\end{array}$ & & & - \\
\hline $\mathrm{Ze}$ & $\begin{array}{l}1980 \\
1994\end{array}$ & $\begin{array}{l}0.0 \\
0.0\end{array}$ & $\begin{array}{l}0.0 \\
0.4\end{array}$ & $\begin{array}{r}5.2 \\
11.2\end{array}$ & $\begin{array}{l}0.8 \\
1.2\end{array}$ & $\begin{array}{l}93.9 \\
87.2\end{array}$ & $\begin{array}{l}727 \\
242\end{array}$ & 11.61 & 1 & $* *$ \\
\hline An & $\begin{array}{l}1980 \\
1994\end{array}$ & $\begin{array}{l}0.0 \\
0.0\end{array}$ & $\begin{array}{l}0.0 \\
0.0\end{array}$ & $\begin{array}{r}8.9 \\
16.0\end{array}$ & $\begin{array}{l}1.4 \\
6.3\end{array}$ & $\begin{array}{l}89.6 \\
77.7\end{array}$ & $\begin{array}{l}694 \\
206\end{array}$ & 24.91 & 2 & $* * *$ \\
\hline Rei & $\begin{array}{l}1978 \\
1992\end{array}$ & $\begin{array}{l}0.0 \\
0.0\end{array}$ & $\begin{array}{l}0.0 \\
0.0\end{array}$ & $\begin{array}{l}5.0 \\
1.9\end{array}$ & $\begin{array}{l}3.6 \\
9.5\end{array}$ & $\begin{array}{l}91.4 \\
88.6\end{array}$ & $\begin{array}{l}695 \\
264\end{array}$ & 11.10 & 2 & $* *$ \\
\hline Jun & $\begin{array}{l}1978 \\
1992\end{array}$ & $\begin{array}{l}21.5 \\
23.0\end{array}$ & $\begin{array}{l}7.0 \\
2.7\end{array}$ & $\begin{array}{l}0.0 \\
0.0\end{array}$ & $\begin{array}{l}0.5 \\
0.0\end{array}$ & $\begin{array}{l}71.0 \\
74.3\end{array}$ & $\begin{array}{r}414 \\
74\end{array}$ & 2.21 & 3 & NS \\
\hline $\mathrm{Wd}$ & $\begin{array}{l}1978 \\
1992\end{array}$ & $\begin{array}{l}4.6 \\
1.6\end{array}$ & $\begin{array}{l}0.6 \\
3.0\end{array}$ & $\begin{array}{l}0.5 \\
0.2\end{array}$ & $\begin{array}{l}0.9 \\
0.6\end{array}$ & $\begin{array}{l}93.4 \\
94.6\end{array}$ & $\begin{array}{r}6902 \\
503\end{array}$ & 46.28 & 3 & $* * *$ \\
\hline $\mathrm{Wa}$ & $\begin{array}{l}1980 \\
1994\end{array}$ & $\begin{array}{l}11.2 \\
12.4\end{array}$ & $\begin{array}{l}1.8 \\
6.2\end{array}$ & $\begin{array}{l}1.4 \\
1.4\end{array}$ & $\begin{array}{l}4.7 \\
0.7\end{array}$ & $\begin{array}{l}80.9 \\
79.3\end{array}$ & $\begin{array}{l}278 \\
145\end{array}$ & 10.34 & 4 & $*$ \\
\hline $\mathrm{Gr}$ & $\begin{array}{l}1980 \\
1994\end{array}$ & $\begin{array}{r}8.6 \\
14.4\end{array}$ & $\begin{array}{l}2.4 \\
1.2\end{array}$ & $\begin{array}{l}5.5 \\
7.0\end{array}$ & $\begin{array}{l}1.8 \\
2.3\end{array}$ & $\begin{array}{l}81.7 \\
75.1\end{array}$ & $\begin{array}{l}454 \\
257\end{array}$ & 8.28 & 4 & NS \\
\hline $\mathrm{Ht}$ & $\begin{array}{l}1980 \\
1994\end{array}$ & $\begin{array}{r}22.2 \\
2.9\end{array}$ & $\begin{array}{l}8.2 \\
6.0\end{array}$ & $\begin{array}{l}0.2 \\
0.0\end{array}$ & $\begin{array}{l}0.8 \\
0.0\end{array}$ & $\begin{array}{l}68.6 \\
91.1\end{array}$ & $\begin{array}{l}526 \\
514\end{array}$ & 75.43 & 1 & $* * *$ \\
\hline $\mathrm{Te}$ & $\begin{array}{l}1978 \\
1992\end{array}$ & $\begin{array}{r}3.5 \\
15.1\end{array}$ & $\begin{array}{l}2.2 \\
0.7\end{array}$ & $\begin{array}{l}0.3 \\
0.7\end{array}$ & $\begin{array}{l}1.9 \\
1.4\end{array}$ & $\begin{array}{l}92.1 \\
82.0\end{array}$ & $\begin{array}{l}630 \\
139\end{array}$ & 3.60 & 4 & NS \\
\hline Ac & $\begin{array}{l}1978 \\
1993\end{array}$ & $\begin{array}{r}13.1 \\
5.9\end{array}$ & $\begin{array}{r}19.8 \\
5.9\end{array}$ & $\begin{array}{l}0.2 \\
0.0\end{array}$ & $\begin{array}{l}0.6 \\
0.0\end{array}$ & $\begin{array}{l}66.3 \\
88.2\end{array}$ & $\begin{array}{r}535 \\
17\end{array}$ & 13.56 & 3 & $* *$ \\
\hline $\mathrm{Br}$ & $\begin{array}{l}1978 \\
1993\end{array}$ & $\begin{array}{l}7.3 \\
4.2\end{array}$ & $\begin{array}{l}3.9 \\
1.0\end{array}$ & $\begin{array}{l}0.0 \\
0.0\end{array}$ & $\begin{array}{l}1.3 \\
0.0\end{array}$ & $\begin{array}{l}87.5 \\
94.9\end{array}$ & $\begin{array}{l}386 \\
311\end{array}$ & 13.56 & 3 & $* *$ \\
\hline
\end{tabular}

TOT, total number of scored plants per year; differences between the years were analysed with a $\chi^{2}$-test.

${ }^{*} P<0.05,{ }^{* *} P<0.01,{ }^{* * * *} P<0.001$. 
Table 2 Sex-type frequencies of Plantago lanceolata (MS1, IN1, MS2, IN2 and $\mathrm{H}$ ) for four populations in several years

\begin{tabular}{lcccccccccc}
\hline Population & Year & MS1 & IN1 & MS2 & IN2 & H & Total & $\chi^{2}$ & d.f. & $P$ \\
\hline REI & 1991 & 0 & 0.1 & 15.6 & 8.0 & 76.3 & 1008 & 43.82 & 4 & $* * *$ \\
& 1992 & 0 & 0 & 2.0 & 0 & 98.0 & 50 & & & \\
\multirow{4}{*}{ NAT } & 1993 & 0 & 1.1 & 17.0 & 20.5 & 61.4 & 176 & & & \\
& 1991 & 14.7 & 0.8 & 4.7 & 0.8 & 78.9 & 360 & 61.27 & 6 & $* * *$ \\
& 1992 & 18.4 & 16.7 & 1.1 & 1.7 & 62.1 & 174 & & & \\
& 1993 & 11.9 & 5.0 & 0 & 0.3 & 82.8 & 337 & & & \\
LEEK & 1994 & 17.1 & 7.1 & 0 & 0.3 & 75.5 & 310 & & & \\
& 1991 & 31.7 & 5.4 & 0.9 & 11.2 & 50.9 & 224 & 103.49 & 12 & $* * *$ \\
& 1992 & 10.7 & 1.6 & 0.8 & 2.4 & 84.5 & 374 & & & \\
VEN & 1993 & 12.8 & 2.6 & 4.3 & 3.4 & 76.9 & 117 & & & \\
& 1994 & 7.8 & 3.9 & 0 & 2.0 & 86.3 & 51 & & & \\
& 1991 & 6.6 & 0 & 15.6 & 3.3 & 70.2 & 366 & 431.58 & 12 & $* * *$ \\
& 1992 & 15.0 & 5.0 & 2.6 & 3.4 & 74.2 & 702 & & & \\
& 1993 & 12.1 & 7.1 & 4.8 & 7.9 & 72.6 & 354 & & & \\
\hline
\end{tabular}

The total number of scored plants per year is shown. The differences in sex-type frequencies among the years were analysed with a $\chi^{2}$-test.

$* * * \mathrm{P}<0.001$.

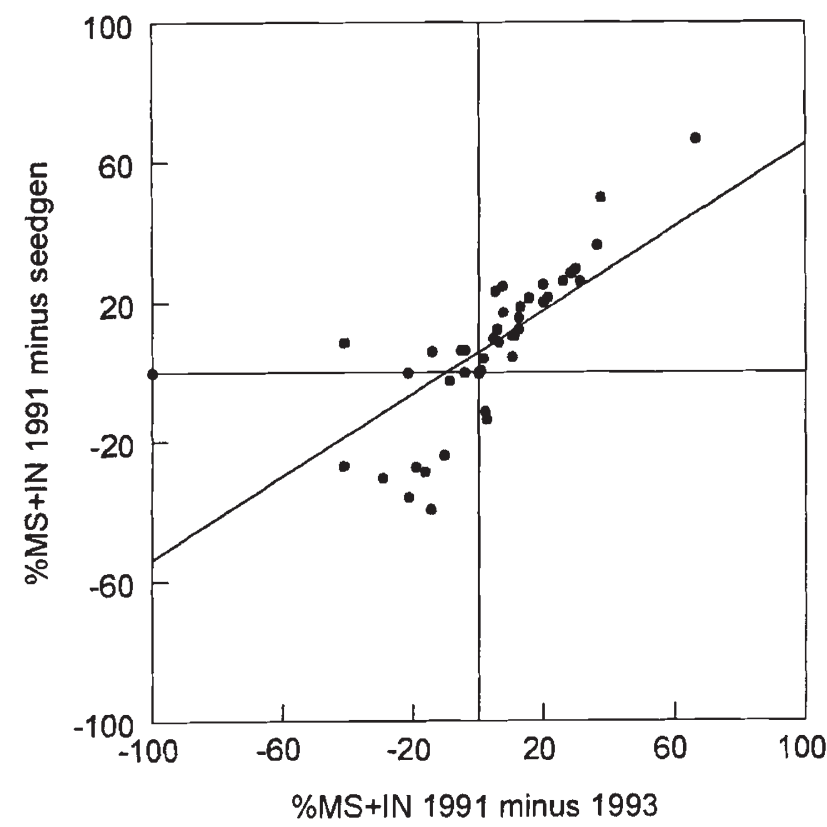

Fig. 1 Male-sterile and intermediate (MS + IN) frequencies of Plantago lanceolata were scored in the field in 1991 and 1993, and in the seed collected in 1991. The seed generation was raised without selection and scored in the experimental garden. Rank correlations of differences in male-sterile + intermediate (MS + IN) frequencies were calculated between the field (1991 minus 1993) and the seed generation (1991 minus 1991). Each point represents a cluster unit (see Materials and methods). tion of mitochondrial patterns (Table 3 ). The lowest level of mtDNA variation was found in Rei, with four mtDNA patterns ( $\mathrm{mt} \mathrm{D}, \mathrm{C}, \mathrm{E}$ and $\mathrm{F}$ ) in 88 plants, of which $\mathrm{mt} \mathrm{C}$ occurred in one individual. Population Nat showed a high level of mitochondrial variation: in total, $11 \mathrm{mtDNA}$ patterns were found in 49 plants. As the size of the sampling areas and the density of plants in Nat and Rei were the same, the variation in Rei was limited compared with Nat.

The frequencies of mtDNA patterns can be used to estimate the frequencies of CMS types. De Haan et al. (1997a; summarized in Table 4) showed that part of the mitochondrial variation is linked with CMS types. In Fig. 3, the frequencies of the CMS types in eight populations are shown, based on the figures in Table 3 . The percentage CMSI was estimated by mtDNA patterns $\mathrm{A}$ and $\mathrm{K}$. Within the CMSII group, CMSIIa and CMSIIb were shown by reciprocal crosses to be different CMS types (Table 4). Other mtDNA patterns represented either one of the CMSII types (Table 4). In this study, we pooled the CMSII types identified as $\mathrm{mt} \mathrm{D}, \mathrm{C}, \mathrm{B}, \mathrm{G}, \mathrm{H}$ and L. The percentage of CMSIII was based on $\mathrm{mt} \mathrm{E}$ and F. Figure 4 shows the percentages of the sex phenotypes in each population. The phenotype frequencies can be compared with the gene frequencies. In two populations, Kou and Rei, in which MS1 was absent and only a few IN1 types were found, CMSI was absent. In the populations $\mathrm{Ht}$ and Jun, in 
which MS1 occurred in high frequencies, CMSI was also frequent. The correlation between the frequency of MS1 and CMSI was high in five populations, with the exception of the population Bm. In $\mathrm{Bm}$, a relatively low MS1 frequency and a relatively high frequency of CMSI was found. The correlation coefficient between MS1 and CMSI was significant only if BM was not taken into account (without Bm: $r=0.94, n=7, P=0.0017$; including Bm: $r=0.61$, $n=8, P=0.111$ ).

The populations Rei, Ven and Leek had been chosen for relatively high frequencies of MS2. No correlation between the frequency of MS2 and the CMSII types together was found $(r=0.35, n=8$, $P=0.40$ ). CMSII types occur in all populations: in Rei mainly CMSIIa; in the other populations both CMSIIa and CMSIIb and unidentified CMSII types.
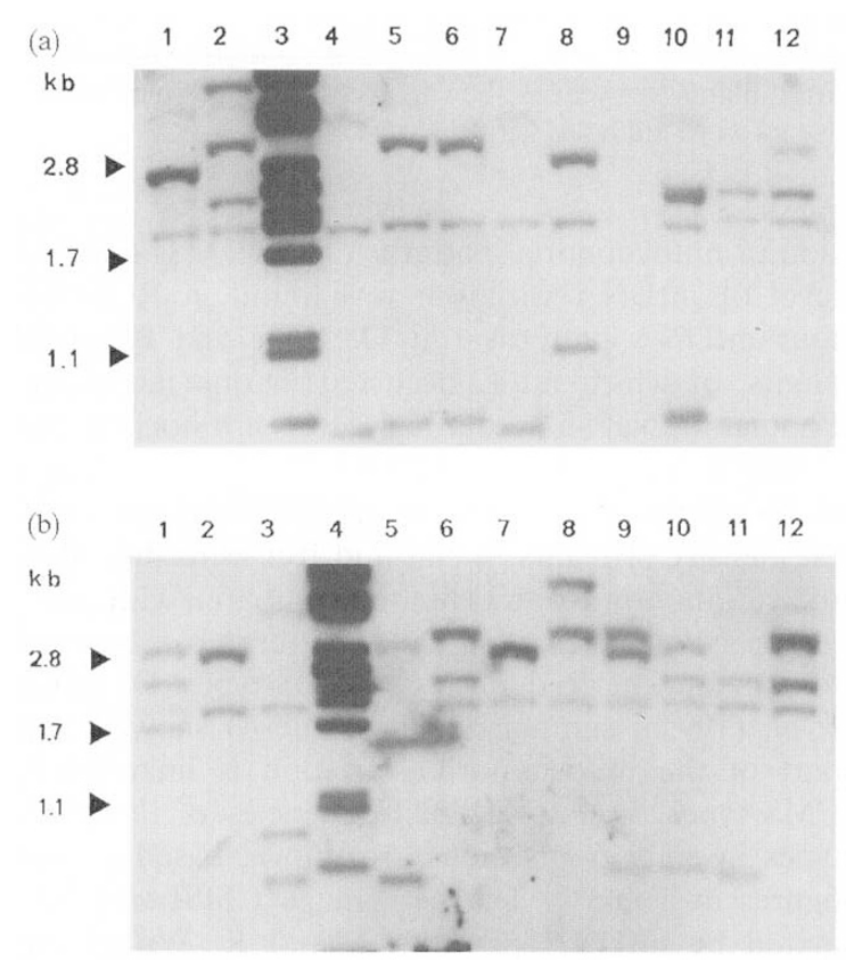

Fig. 2 (a) Ten mtDNA patterns (HindIII probed with pPl311 P. lanceolata $\mathrm{mt}$ probe) of 10 Plantago lanceolata plants: lane numbers 1,2 and 4-12. In lane 3 a molecular weight marker is shown, lambda digested with Pst I. Lane 1 shows mtDNA pattern $\mathrm{C}$, lane $2 \mathrm{mt} \mathrm{B}$. Lanes 4 and $7 \mathrm{mt}$ $\mathrm{A}$, lanes 5 and $6 \mathrm{mt} \mathrm{G}$, lane $8 \mathrm{mt} \mathrm{L}$, lane 10 a new mtDNA pattern $(\mathrm{mt} \mathrm{N})$, lane $11 \mathrm{mt} \mathrm{E}$, lane $12 \mathrm{mt} \mathrm{F}$. (b) Ten mtDNA patterns (HindIII probed with pPI311 $P$. lanceolata $\mathrm{mt}$ probe) of $10 \mathrm{P}$. lanceolata plants: lane numbers $1-3$ and 5-12. In lane 4 a molecular weight marker is shown, lambda digested with PstI. Lane 9 shows mtDNA pattern D; the other lanes show new mtDNA patterns.
The MS2 frequencies therefore cannot be explained only by the CMS-type frequencies. In Kou, MS1 and MS2 were absent and only 23 IN2 types were found out of 774 individuals. Here CMSI was absent, CMSII types had a low frequency and the frequency of CMSIII was high. In Rei, a high frequency of CMSIII was also found and CMSI was absent.

The data shown in Figs 3 and 4 can be used to estimate the restorer frequency. The difference between the percentage CMSI and MS1 indicates the overall restorer frequency. For both CMSI and CMSII (all types together), the estimated restorer frequencies are given in Table ${ }^{5} p \mathrm{R}_{i}$ showed the same differences among populations if $p \mathrm{MS}_{i}$ was based on the sample year or based on the average of 4 years (results not shown), therefore the average of 4 years was taken as a better estimate of $p \mathrm{MS}_{i}$. Furthermore, the observed restorer frequency per mtDNA pattern can be assessed based on the sex phenotypes of the plants whose mtDNA pattern was screened (see Materials and methods). The sample sizes were limited. Significant differences were found between the restorer frequencies among the mtDNA patterns $\left(F_{15,84}=4.47, P<0.001\right)$ : mtDNA pattern $\mathrm{K}$ was significantly different from the other mtDNA patterns (LSD test, $P<0.05$ ). Also, if the mtDNA patterns were grouped together in CMS types, the restorer frequencies differed significantly among CMS types $\left(F_{3,135}=10.13, P<0.001\right)$ and the restorer frequency for CMSI was significantly lower (LSD test, $P<0.05)$.

\section{Discussion}

\section{Dynamics of gynodioecy}

We found significant differences in sex phenotype frequencies between years both on a small timescale ( 3 years) and in the long-term (12 years). The differences among years could result from (1) differences in sex expression between years, (2) differential flowering of sex phenotypes between years or (3) changes in the genotype composition of the populations.

1 In contrast to MS and $H$, sex phenotype IN can be mistaken for MS or $\mathrm{H}$ depending on the environmental conditions (Van Damme \& Van Delden, 1982; De Haan, 1996). Because the expression of MS and $\mathrm{H}$ is not influenced by the environment, differences in sex expression are an unlikely explanation.

2 The populations Rei and Ven were screened weekly in 1993. Those results (not shown) indicated that the number of flowering plants changes during 
Table 3 The number of screened Plantago lanceolata with mtDNA patterns A to $\mathrm{L}$ per population revealed by HindIII and $P$. lanceolata $\mathrm{mt}$ probe pPI311 (mt). The mtDNA patterns are categorized by their CMS type: CMSI (mt A and K), CMSIIa (mt D), CMSIIb (mt C), CMSII (mt B, G, H, L), CMSIII (mt E, F), unidentified (unid, rest)

\begin{tabular}{lrrrrrrrrrr}
\hline & \multicolumn{2}{c}{ CMSI } & & & \multicolumn{2}{c}{ CMSII } & & \\
POP & mt A & mt K & $\begin{array}{c}\text { CMSII } \\
\text { mt D }\end{array}$ & $\begin{array}{c}\text { CMSIIb } \\
\text { mt C }\end{array}$ & mt BGH & mt L & $\begin{array}{c}\text { CMSIII } \\
\text { mt EF }\end{array}$ & $\begin{array}{r}\text { unid } \\
\text { rest }\end{array}$ \\
\hline KOU & 0 & 0 & 0 & 1 & 2 & 0 & 10 & 1 \\
REI & 0 & 0 & 56 & 1 & 0 & 0 & 31 & 0 \\
VEN & 13 & 0 & 7 & 12 & 31 & 42 & 5 & 28 \\
LEEK & 8 & 9 & 8 & 3 & 12 & 0 & 0 & 19 \\
NAT & 17 & 1 & 7 & 2 & 13 & 0 & 4 & 5 \\
BM & 20 & 0 & 1 & 12 & 1 & 0 & 1 & 0 \\
HT & 28 & 0 & 3 & 26 & 27 & 0 & 1 & 4 \\
JUN & 15 & 3 & 11 & 10 & 1 & 0 & 2 & 0 \\
\hline
\end{tabular}

the season, but this does not affect the estimation of sex phenotype frequencies, implying that at least during the season there is no differential flowering of sex phenotypes.

3 However, a positive correlation between changes in the field and the differences between the field population and its seed generation indicates that changes in genotype composition occur over generations. The annual turnover of $P$. lanceolata is known for two of the studied populations - $\mathrm{Ht}$ with 5 per cent and Wd with 50 per cent - whereas the range in the other unstudied populations has been

Table 4 CMS types found in Plantago lanceolata after reciprocal crosses between hermaphrodites with different mt-patterns. For each CMS type, the male-sterile phenotype is indicated (based on De Haan et al., 1997a)

\begin{tabular}{lcc}
\hline CMS type & Mt-pattern & Morphology \\
\hline CMSI & A & MS1 \\
& K\$ & MS1 \\
CMSIIa & D & MS2 \\
b & C & MS2 \\
b/c* & B & MS2 \\
a $/$ b $/ c^{\dagger}$ & G,H,L & MS2 \\
CMSIII & E, F & $($ MS3) $\ddagger$ \\
\hline
\end{tabular}

*Plants with $\mathrm{mt}$-pattern $\mathrm{B}$ are different from D, possibly different from $\mathrm{C}$.

$\nmid$ Plants with G,H,L could not be categorized, but according to their morphology they are CMSII.

$\$$ Probably is MS3 independent of CMS type (only nuclear genes involved) and occurs also in CMSI and II.

§Mt-pattern $\mathrm{K}$ could not be categorized, but according to the male-sterile phenotype (MS1) it was assumed to be a CMSI type. reported to be 25-40 per cent (Van Dijk et al., 1988). Thus, despite the relatively long lifespan of plants in several populations, a continuous replacement of individuals takes place.

This last finding favours the two hypotheses that predict a dynamic process within a population. This does not, of course, exclude the possibility that environmental factors could be important in the maintenance of gynodioecy. Krohne et al. (1979) found a correlation between soil moisture and the

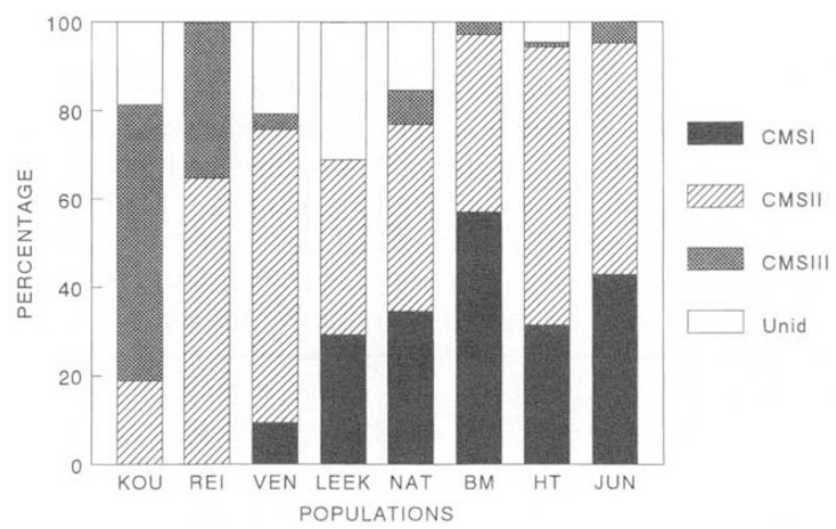

Fig. 3 The CMS-type composition per population of Plantago lanceolata. MtDNA patterns were used as markers for CMS types (Table 5). The percentages of the CMS types were based on the numbers of mtDNA patterns found in the samples taken from those populations. Mt A and $\mathrm{mt} \mathrm{K}$ from Table 3 were used to calculate the percentage CMSI; $\mathrm{mt} \mathrm{D}, \mathrm{C}, \mathrm{B}, \mathrm{G}, \mathrm{H}$ and $\mathrm{L}$ in Table 3 were used to calculate the total of CMSII types (no distinction between CMSIIa, CMSIIb and other types was made); the numbers of mtDNA patterns $E$ and $F$ were used to calculate CMSIII, and the percentages of new mtDNA patterns are shown as unidentified (unid). 
frequency of male-steriles in $P$. lanceolata. Furthermore, in $P$. lanceolata it was found that in wet hayfields the frequency of one of the two malesterile types was high, whereas the other type was absent (Van Damme \& Van Delden, 1982). However, Van Damme \& Graveland (1985) could not find fitness differences between male-steriles and hermaphrodites under different environmental

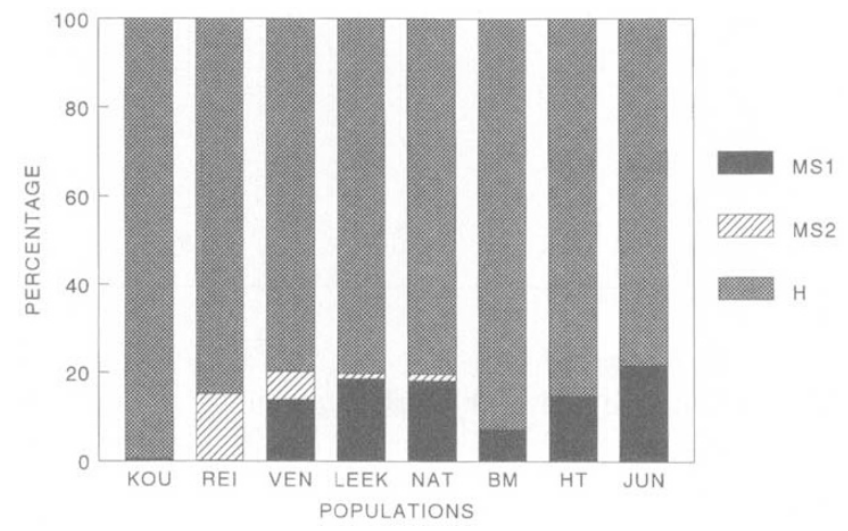

Fig. 4 The sex phenotype composition per population of Plantago lanceolata. The numbers of MS1 and IN1 averaged over years from Table 2 were used to calculate the percentage MS1 + IN1. The numbers of MS2 and IN2 averaged over years from Table 2 were used to calculate the percentage of MS2 + IN2. The percentage of hermaphrodites $(H)$ was based on the numbers of $H$ in Table 2 averaged over years per population. conditions, which would explain the high frequencies of male-steriles in wet hayfields, in the field and in the greenhouse experiments.

\section{Gene frequencies: CMS type and restorer alleles}

Changes in sex phenotype composition within populations have been predicted by two theoretical models: those posited by Frank (1989) and Gouyon et al. (1991). The number of CMS types and their distribution over populations are important factors for distinguishing between the two models. Here, the the possible number of CMS types and their distribution will be discussed.

In mtDNA there is a large potential for variation. New CMS types can arise from mutations in the mtDNA. Recombination between small and large repeats can give rise to rearrangements (Lonsdale et al., 1988). A high degree mitochondrial variation has been found in most natural populations of gynodioecious species (Belhassen et al., 1991; Cuguen et al., 1994; Ronfort et al., 1995). Variation has also been found in crops (e.g. Kemble et al., 1983; Weihe et al., 1991). In P. lanceolata, the level of mtDNA variation was screened in eight populations with the enzyme-probe combination HindIII-pPl311. Because small differences between mtDNA patterns were not taken into account, the level of mtDNA variation was probably underestimated. De Haan et al. (1997a) showed by reciprocal crosses that out of

Table 5 For eight populations of Plantago lanceolata the frequencies of restorers are shown. The estimated restorer (est) frequencies for CMSI and CMSII were calculated as described in Materials and methods. The observed (obs) restorer percentages for the CMSI mtDNA patterns $\mathrm{mt} \mathrm{A}$ and $\mathrm{K}$ are shown separately (\% $\mathrm{R} \mathrm{mt} \mathrm{A}$ obs; \% $\mathrm{R} \mathrm{mt} \mathrm{K}$ obs). The restorer percentage was based on $n$ plants, or $n$ families of 10 plants (see Materials and methods). The observed

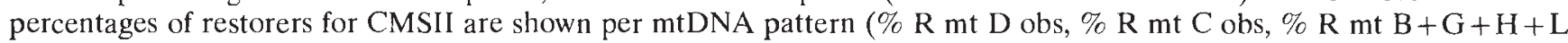
obs, respectively). The numbers of plants used to estimate the observed percentages are shown, as number of plants or number of families of plants $(n)$ (see Materials and methods)

\begin{tabular}{|c|c|c|c|c|c|c|c|c|c|c|}
\hline Population & $\begin{array}{c}\% \mathrm{R} \\
\mathrm{CMSI} \\
\text { est }\end{array}$ & $\begin{array}{c}\% \mathrm{R} \\
\mathrm{CMSII} \\
\text { est }\end{array}$ & $\begin{array}{c}\% \mathrm{R} \\
\mathrm{mt} \\
\mathrm{A} \\
\text { obs }\end{array}$ & $\begin{array}{c}n \\
\mathrm{mt} \\
\mathrm{A}\end{array}$ & $\begin{array}{c}\% \mathrm{R} \\
\mathrm{mt} \\
\mathrm{K} \\
\text { obs }\end{array}$ & $\begin{array}{c}n \\
\mathrm{mt} \\
\mathrm{K}\end{array}$ & $\begin{array}{c}\% \mathrm{R} \\
\mathrm{mt} \\
\mathrm{D} \\
\text { obs }\end{array}$ & $\begin{array}{c}\% \mathrm{R} \\
\mathrm{mt} \\
\mathrm{C} \\
\text { obs }\end{array}$ & $\begin{array}{c}\% \mathrm{R} \\
\text { BGHL } \\
\text { obs }\end{array}$ & $\begin{array}{c}n \\
\mathrm{mt} \\
\mathrm{DCGH} \\
\mathrm{L}\end{array}$ \\
\hline KOU & 0 & 18.8 & -- & - & - & - & - & 100 & 100 & 17 \\
\hline REI & 0 & 36.0 & - & - & - & - & 55 & - & - & $44^{*}$ \\
\hline VEN & 0 & 59.9 & 72 & $5^{*}$ & - & - & 82 & 72 & 74 & $25^{*}$ \\
\hline LEEK & 8.0 & 62.6 & - & - & 34 & $9 *$ & 91 & 80 & 84 & $37^{*}$ \\
\hline NAT & 19.5 & 40.7 & 76 & $7^{*}$ & 0 & $1^{*}$ & 100 & 50 & 84 & $33^{*}$ \\
\hline BM & 49.9 & 40.1 & 63 & $10^{*}$ & - & - & - & 78 & - & $22^{*}$ \\
\hline HT & 16.7 & 62.9 & 90 & 24 & - & - & 100 & 100 & 96 & 64 \\
\hline JUN & 21.2 & 52.4 & 100 & 11 & 100 & 10 & 100 & 100 & 100 & 33 \\
\hline Mean & & & 69 & & 30 & & 92 & 74 & 82 & \\
\hline
\end{tabular}

*Number of families each of 10 plants. 
nine mtDNA patterns at least four were indicative of different CMS types (Table 4). There are several indications that there might be more. The mtDNA patterns $\mathrm{A}$ and $\mathrm{K}$ were found in MS1 plants. Both patterns were used to estimate the frequency of CMSI. It is possible that $\mathrm{mt} \mathrm{K}$ and $\mathrm{mt} \mathrm{A}$ represent different CMS types: the restorer frequency for $\mathrm{mt}$ $\mathrm{K}$ was significantly lower than for $\mathrm{mt} \mathrm{A}$. However, those restorer frequencies could not be determined within one population, and therefore the observed differences could also be caused by differences in restorer frequencies for CMSI between populations. Only reciprocal crosses can give a definite answer about possible differences between $\mathrm{mt} \mathrm{A}$ and $\mathrm{mt} \mathrm{K}$.

Several mtDNA patterns were found in MS2 plants (Groenendijk et al., 1997). De Haan et al. (1997a) showed that at least two CMS types occur among those plants: CMSIIa (mt D) and CMSIIb $(\mathrm{mt} \mathrm{C})$. Some indications of more CMS types were found: $\mathrm{mt} \mathrm{B}$ and $\mathrm{mt} \mathrm{L}$ may represent new CMS types (De Haan, 1996). For the estimation of the frequencies of the CMSII types, we chose to pool all the mtDNA patterns that were found in MS2 plants and obtained an overall estimate of CMSII. For the estimation of the CMSIII frequency, the mtDNA patterns $\mathrm{E}$ and $\mathrm{F}$ were used.

The distribution of CMSI was significantly correlated with the frequency of MS1 if population $\mathrm{Bm}$ was not taken into account. In addition, the frequency of the restorer alleles for CMSI was significantly lower than for the other CMS types. In the exceptional population $\mathrm{Bm}$, a high frequency of CMSI was found together with a low frequency of MS1. This must be caused by a high frequency of restorer alleles for CMSI, which was indeed found by De Haan et al. (1997b).

Whereas CMSI occurs only in populations in which MS1 was found, CMSII types were found in all populations, independent of the occurrence of MS2. Both CMSIIa and CMSIIb were found in various ratios in most populations. CMSIII occurred at a high frequency in the populations Rei and Kou. CMSI was absent from these populations. In the other six populations, CMSI was present and CMSIII occurred only at a very low frequency. It seems that CMSI and CMSIII partly exclude each other.

Restorers for CMSI were less frequent than restorers for CMSII types. In other species it was found that some CMS types occurred mainly in male-steriles and other CMS types mainly in hermaphrodites (in Beta maritima, Cuguen et al., 1994; in Plantago coronopus, Koelewijn \& Van Damme, 1995). Furthermore, we found that CMSIII occurred at high frequencies only in populations in which CMSI was absent.

\section{Data and theory}

At least four CMS types are present in P. lanceolata, possibly more. This is in agreement with the model of Frank (1989), and does not violate the model of Gouyon et al. (1991). Frank (1989) used nine CMS types in the model, but the lower limit of the number of CMS types necessary for maintenance is unknown. From the Frank (1989) model it is expected that in different populations different CMS types occur at high frequency and that a CMS type will be highly restored in one population but not in another. However, we found that some CMS types are largely restored, whereas for the CMSI type the restorer frequency is low. Moreover, De Haan et al. (1997a) showed that the main male-sterile in many populations (also outside the Netherlands) seems to be CMSI. This result can be explained only partly by the theoretical models.

Three hypotheses were put forward to explain the different MS frequencies in populations and although none of them can be excluded, nor do any of them fully explain the data.

Environmental variation between populations cannot be excluded, but changes over time within populations have been shown to occur, which makes this hypothesis a less likely explanation.

The number of CMS types might be sufficiently high in $P$. lanceolata to explain the maintenance of gynodioecy with Frank's (1989) model. However, the trend over populations for CMSI to occur in most populations as the main male-sterile does not fit with the Frank model, but hypothesis (3) can be explained by the model of Gouyon et al. (1991) if asymmetric values are assumed. However, in this model the 'MS fitness advantage' and the 'cost of restoration' need to be high compared with Frank's model. De Haan et al. (1997c) showed that the assessed values for these parameters might not be high enough to explain the maintenance of gynodioecy.

\section{Acknowledgements}

A. A. D. H. was supported by the Netherlands Organization for the Advancement of Research (NWO). We thank M. P. J. Hundscheid for practical assistance, H. Smouter for giving us seed material from his experiment, A. van Hinsberg for his advice on some of the statistics and P. J. Van Dijk for critically reading an earlier version of the manuscript. 


\section{References}

Belhassen, E., trabaud, L. AND Couvet, D. 1989. An example of nonequilibrium processes: gynodioecy of Thymus vulgaris L. in burned habitats. Evolution, 43, 662-667.

Belhassen, E., DOMMEE, B., ATlan, A., GOUYON, P.-H., POMENTE, D., ASSOUAD, M. W. AND COUVET, D. 1991. Complex determination of male sterility in Thymus. vulgaris L.: genetic and molecular analysis. Theor. Appl. Genet., 82, 137-143.

BRAUN, C. J., BROWN, G. G. AND LEVINGS, C. S., III. 1992. Cytoplasmic male sterility. In: Hermann, R. G. (ed.) Cell Organelles, pp. 219-245. Springer, New York.

CHARlesworTh, B. AND CHARLESWORTH, D. 1978. A model for the evolution of dioecy and gynodioecy. Am. Nat., 112, 975-997.

COUVET, D., BONNEMAISON, F. AND GOUYON, P.-H. 1986. The maintenance of females among hermaphrodites: the importance of nuclear-cytoplasmic interactions. Heredity, 57, 325-330.

Couvet, D., ATlan, A., Belhassen, E., Gliddon, C., GOUYON, P.-H. AND KJElllbERG, F. 1990. Co-evolution between two symbionts: the case of the cytoplasmic male-sterility in higher plants. In: Futuyama, D. and Antonovics, J. (eds) Oxford Surveys in Evolutionary Biology, vol. 7, pp. 225-245. Oxford University Press, Oxford.

CUGUEN, J., WATTIER, R,, SAMITOU-LAPRADE, P., FORCIOLI, D., MORChen, M., VAN DIJK, H. AND Vernet, Ph. 1994. Gynodioecy and mitochondrial DNA polymorphism in. natural populations of Beta vulgaris ssp. maritima. Génét. Sél. Évol., 26, 87-101.

DE HAAN, A. A. 1996. The Maintenance of Male Sterility in Plantago lanceolata $L . \mathrm{PhD}$ thesis, University of Utrecht.

DE haAn, A. A., MATEMAN, A. C., VAN DIJK, P. J. AND VAN DAMmE, J. M. M. 1997a. New CMS types in Plantago lanceolata and their relatedness. Theor. Appl. Genet., 94, 539-548.

DE. HAAN, A. A., KOELEWŸN, H. P., HUNDSCHEID, M. P. J. AND VAN DAMME, J. M. M. 1997b. Dynamics of gynodioecy in Plantago lanceolata L. II. Mode of action and frequencies of restorer alleles. Genetics, (in press).

DE HAAN, A. A., HUNDSCHEID, M. P. J. AND VAN HINSBERG, A. 1997c. Effects of CMS types and restorer alleles on plant performance in Plantago lanceolata: an indication of costs of restoration. J. Evol. Biol., 10, (in press).

FRANK, s. 1989. The evolutionary dynamics of cytoplasmic male sterility. Am. Nat., 133, 345-376.

GOUYON, P.-H., VICHOT, F. AND VAN DAMME, J. M. M. 1991. Nuclear-cytoplasmic male sterility: single-point equilibria vs. limit cycles. Am. Nat., 137, 498-514.

GROENENDIJK, C. F. M., SANDBRINK, J. M., VAN BREDERODE, J. AND VAN DAMME, J. M. M. 1997. Mitochondrial DNA variation within P-type cytoplasmic male sterility of Plantago lanceolata L. Heredity, 78, 75-83.

HANSON, M. R. AND CONDE, M. F. 1985. Functioning and variation of cytoplasmic genomes: lessons from cyto- plasmic-nuclear interactions affecting male fertility in plants. Int. Rev. Cytol., 94, 213-267.

KEMBLE, R. J., GUNN, R. E. AND FLAVELL, R. B. 1983. Mitochondrial DNA variation in races of maize indigenous to Mexico. Theor: Appl. Genet., 65, 129-144.

KOELEWIJ, H. P. AND VAN DAMME, J. M. M. 1995. Genetics of male sterility in gynodioecious Plantago coronopus. I. Cytoplasmic variation. Genetics, 139, 1749--1758.

KROHNE, D. T., BAKER, I. AND BAKER, H. G. 1979. The maintenance of the gynodioecious Plantago lanceolata L. Am. Midl. Nat., 103, 269-279.

LoNSDAlE, D. M., BREARS, T., HODGE, T. P., MELVILLE, S. A. AND ROTTMANN, w. H. 1988. The plant mitochondrial genome: homologous recombination as a mechanism. for generating heterogeneity. Phil. Trans. R. Soc. B, 319, 149-163.

MOOK, J., HAECK, J., VAN DER TOORN, J. AND VAN TIENDEREN, P. H. 1992. The demographic structure of populations. In: Kuiper, P. J. C. and Bos, M. (eds) Plantago: a Multidisciplinary Study, pp. 69-87. Ecological Studies 89. Springer, Berlin.

ROGERS, S. O. AND BENDICH, A. J. 1988. Extraction of DNA from plant tissues. Pl. Mol. Biol. Manual A6, 1-10.

RONFORT, J., SAMITOU-LAPRADE, P., CUGUEN, J. AND COUVET, D. 1995. Mitochondrial DNA diversity and male sterility in natural populations of Daucus carota ssp. carota. Theor. Appl. Genet., 91, 150-159.

Ross, M. D. 1980. The evolution and decay of overdominance during the evolution of gynodioecy, subdioecy, and dioecy. Am. Nat., 116, 607-620.

ROUWENDAL, G. J. A., VAN DAMME, J. M. M. AND WESSELS, J. G. H. 1987. Cytoplasmic male sterility in Plantago lanceolata L.: differences between male sterile cytoplasms at the DNA- and RNA-level. Theor. Appl. Genet, 75, 59-65.

VAN DAMME, J. M. M. 1983. Gynodioecy in Plantago lanceolata L. II. Inheritance of three male sterility types. Heredity, 50, 253-273.

VAN DAMME, J. M. M. AND GRAVEland, J. 1985. Does cytoplasmic variation in Plantago lanceolata contribute to ecological differentiation? In: Jacquard, P. (ed.) Genetic Differentiation and Dispersal in Plants, pp. 67-79. NATO ASI series, vol. G5. Springer, Berlin.

VAN DAMME, J. M. M. AND VAN DELDEN, w. 1982. Gynodioecy in Plantago lanceolata L. I. Polymorphism for plasmon type. Heredity, 49, 303-318.

VAN DIJK, H., WOLFF, K. AND DE VRIES, A. 1988. Genetic variability in Plantago species in relation to their ecology. Part 3. Genetic structure of populations of $P$. major, $P$. lanceolata and $P$. coronopus. Theor. Appl. Genet., 75, 518-528.

Weihe, A., Dudareva, N. A., Veprev, S. G., MALetsky., S. I., MELZER, R., SALGANIK, R. I. AND BÖRNER, T. H. 1991. Molecular characterization of mitochondrial DNA of different subtypes of male-sterile cytoplasms of the sugar beet Beta vulgaris L. Theor. Appl. Genet., 82, 11-16. 